\title{
INFLUENCE OF ADHESIVE SYSTEMS ON BOND STRENGTH OF RESIN COMPOSITE TO ER,CR :YSGG LASED DENTIN UNDER SIMULATED PULPAL PRESSURE
}

\author{
UlaA A. FATHI and MAAN M. NAYIF \\ Dept. of Conservative Dentistry, College of Dentistry, Mosul University, Mosul-Iraq.
}

(Accepted for Publication: August 29, 2019)

\begin{abstract}
Objective: The Objective Of This Study Was To Evaluate The Effect Of Different Adhesive Systems On Conventional Tensile Bond Strength (Ctbs) Of Composite Bonded To Dentin Prepared With Er,Cr:Ysgg Laser Under Simulated Pulpal Pressure (Spp).

Materials And Methods: Crowns Of Eighteen Molars Were Sectioned Then Dentin Exposed And Prepared With Er,Cr:Ysgg Laser. The Coronal Pulp Chember Were Connected To Barrel At 15mm Hight For Simulating Pulpal Pressure System. Dentin Were Treated With Three Systems: Total Etch (Adper Single Bond 2, 3m, Epse, Usa); One Step Self-Etch (Adper Easy One, 3m Epse, Usa); Two Steps Self-Etch (Clearfil Se Bond, Kurary Medical, Germany ). Resin Composite Build Up And Connected To Small Metal Screw. Samples Were Stored In Distilled Water At $37^{\circ} \mathrm{C}$ For 24 Hours. Ctbs Was Measured Using Universal Testing Machine (Digital Force Gauge Imada Co., Ltd, Japan) At A Crosshead Speed Of $0.5 \mathrm{Mm} /$ Min. Data Analysed With One Way Anova At $\mathbf{P}<0.05$.

Results: The One Way Anova Reveared That There Was No Significant Difference In Ctbs Regardless Of Adhesive System Used For Composite (P>0.05).

Conclusions: Different Adhesive Systems Have No Influence On The Resin Composite Bond Strength To Er,Cr:Ysgg Lased Dentin Under Simulated Pupal Pressure.
\end{abstract}

KEY WORDS: Adhesives, Bond strength, Pulpal pressure, laser

\section{INTRODUCTION}

With the advancement of laser technology and devices different kinds of lasers may be used for preparing cavities. The family of Erbium lasers considered the most efficient and safe systems and include Er:YAG laser $(2.94 \mu \mathrm{m})$ and Er,Cr:YSGG laser $(2.78$ $\mu \mathrm{m})$. Such wavelength absorbed by water and hydroxyapatite within tooth structure causes micro-explosions (Obeidi et al., 2010). Irradiation of dentin with Er,Cr:YSGG lasers will remove smear layer, exposing dentinal tubules, creating a surface with a different characteristics in comparison to those treated with bur with more acid-resistant roughened dentin surfaces (Youssef et al., 2008; Buyukhatipoglu et al.2016).

Moist condition and dentin permeability are factors contributing in the bonding strength of restorative materials to dentin (Davari et al., 2013). It has been reported that dentin fluid movement and wetness from tubular fluid lowers bond strength (Nakajima et al., 2006; Hosaka et al., 2007). These led to recommendation to test the bond strength under pulpal pressure to obtain more relevant result. Existence of water is unavoidable when bonding to dentin thus dentin adhesives should be compatible with wet dentin substrates. The tubular occlusion of dentin surface by laser irradiation might affect the bonding of adhesive restoration when placed under SPP (Tay et al., 2005). Currently, the most commonly used adhesive systems are etch and rinse and self-etching which designed to reduce the number of steps of the bonding protocol. Some of these systems are based on hydrophilic resin monomers, usually 2hydroxyethyl methacrylate (HEMA), associated or not with hydrophobic dimethacrylates, as bisphenol A diglycidyl methacrylate (Bis-GMA) while other systems like all in one contain water in their composition(Karadas and Caglar 2017; Breschi et al, 2018). Therefore it is important to understand the behavior of different systems when dentin prepared with laser with presence of 
water content. The hypothesis to be tested in this study is that there is no difference in CBS of resin composite restoration to the dentin irradiated with Er,Cr:YSGG laser when treated with different adhesive systems under SPP .Thus the purpose of this study was to evaluate the effect of different adhesive systems on CBS of composite resin to laser treated dentin under simulated SPP.

\section{MATERIALS AND METHODS}

\section{Sample collection and preparation:}

Eighteen freshly extracted human third molars collected from patients between 18 and 25 years old. Teeth were cleaned with hand scaling and stored in distilled water until their use within one week. The whole occlusal enamel was abraded using trimmer under water cooling until the underlining superficial dentin exposed. Dentin surfaces were polished using 400 grit water proof aluminum oxide polishing paper to standardized smear layer. Crowns were sectioned at cement enamel junction. Pulp tissue remnants were carefully cleaned from pulp chamber, washed with distilled water. Crowns were adhered to translucent plastic piece $(1 \times 5$ $\mathrm{cm}$ and $1.5 \mathrm{~mm}$ thickness) using super glue. Dentin surfaces were covered with adhesive tape punched at center with hole of $4.0 \mathrm{~mm}$ in diameter Figure (1).

\section{Laser treatment:}

Samples were fixed to surveyor with modified arm for fixation of laser tip distance, angle and movement. Exposed surface of the dentin was treated with Er,Cr:YSGG ( Waterlase iplus, BIOLASE Technology, USA)) with the following parameter as determined in pilot study ( $2780 \mathrm{~nm}$ wavelength, a pulse duration 140 $200 \mu \mathrm{s}$, a pulse repetition rate of 20 pulses per second $(20 \mathrm{~Hz}), 2.75 \mathrm{~W}$ power, $80 \%$ air spray and $70 \%$ water spray). Laser energy was delivered through fiber-optic system to a sapphire tip of $0.6 \mathrm{~mm}$ diameter and $6 \mathrm{~mm}$ long (MZ6). A non-contact mode at $1 \mathrm{~mm}$ distance with sweeping movement for 20s was applied during preparation.

\section{Pulpal pressure application and Bonding procedure:}

A syringe needle was inserted through the plastic piece to the pulp chamber and fixed in place with glue. Samples were connected to SPP system by connecting $5 \mathrm{~mL}$ barrel filled with distilled water to the fixed syringe needle using flexible plastic tube. Dentin was bonded under SPP after adjusting the height of the water column to $15 \mathrm{~cm}$ above the dentin surface level to provide $15 \mathrm{~cm} \mathrm{H}_{2} \mathrm{O}$ pressure. Samples were subdivided into three groups according to the type of bonding system. Adhesives selected represent the most commonly used and efficient systems for resin composite restorations: Total etch (Adper Single Bond 2, 3M, ESPE, USA); One step self-etch (Adper Easy One, 3M, ESPE, USA); Two step self-etch (Clearfil SE Bond, kuraray Medical, Germany). Compositions of adhesive system are showed in Table (1). All adhesives were applied according to manufacture instructions. A translucent plastic tube with $4 \mathrm{~mm}$ diameter and $4 \mathrm{~mm}$ height was fixed onto central region of dentin surface using sticky wax. Hybrid resin composite (Filtek Z250, 3M Co., St. Paul, MN, USA) was incrementally applied onto plastic tube up to $2 \mathrm{~mm}$ and cured for $20 \mathrm{sec}$ from buccal and lingual direction using LED light-curing unit with a light intensity of $500 \mathrm{~mW} / \mathrm{cm}^{2}$. A second layer was applied and small metal screw with ring head was embedded in perpendicular position followed by curing the composite as in first layer. Plastic tube surrounding the composite was carefully removed with the aids of surgical blade. Samples were stored in distilled water at $37^{\circ} \mathrm{C}$ for 24 hours.

\section{Tensile bond strength test:}

Sample crowns were gripped by clamp of universal testing machine (Digital Force Gauge IMADA CO., LTD, Japan) and the ring was connected to the upper hook of the device. A tensile force was applied at a crosshead speed of $0.5 \mathrm{~mm} /$ minute until debonding and value were calculated and recorded in newten.

\section{Failure mode:}

Following testing procedure, the mode of failures between composite and dentine surface was determined. The failures modes were classified as follow: Adhesive failure (dentin exposed); Cohesive failure (composite or adhesive observed on dentin); and Mixed failure (combination of adhesive and cohesive). The modes of failures were determined by taking picture to the dentin surface at $20 \mathrm{X}$ magnification using a Stereomicroscope (Motic, Italy) Karadas and Çaglar (2017). 


\section{Statistical analysis:}

Statistical analysis was made using the Statistical Package for the Social Sciences (SPSS 18.0, SPSS Inc., USA). One Way ANOVA was used to evaluate the difference in tensile bond strength of three different adhesive systems $\mathrm{p}<0.05$.

\section{RESULTS}

The mean values of the conventional tensile bond strength of resin composite restoration bonded with three adhesive systems to Er,Cr:YSGG lased dentin under simulated pulpal pressure are presented in Figure (2). One Way ANOVA demonstrated that the tensile bond strength of composite resin to the dentin surface was not significantly different regardless of adhesive system used $(\mathrm{P}>0.05)$. Table (1) shows the result of One Way ANOVA for bond strength of different adhesive systems under pulpal pressure. For failure mode analysis it has been shown that within the three investigated adhesives the most failure mode was adhesive $(60 \%)$ while remaining was mixed $(40 \%)$.

\section{DISCUSSION}

The wetness of dentin surfaces utilizing pulpal pressure are extremely important variable during bonding procedures to prepared dentin when intend to simulate in vivo conditions ( Hashimoto et al., 2004). In a wet bonding technique water will keep the demineralized collagen network open during primer infiltration (Hashimoto et al., 2006). Authors have studied the bonding of adhesives to dentin by simulating pressures ranging from 30 to $37 \mathrm{~cm} \mathrm{H} 2 \mathrm{O}$ (Gernhardt et al., 2005; Moll et al., 2005). It has been stated that average value of approximately $15 \mathrm{~cm} \mathrm{H}_{2} \mathrm{O}$ should be used to simulate a hyperemic pulp condition (Rosales-Leal, et al. 2007; Cardoso, et al. 2008). It has been reported that the Er, Cr: YSGG ablated dentin surface was free from any smear layer which is an essential factor regulating water movement through dentinal tubules. Under pulpal pressure this condition may be aggravated resulting more amount of water pass through dentinal tubules to the ablated dentin surface making surface over wet and hampering the optimal interaction between the adhesive and the dentin substrate ( Hosaka, et al. 2007; Sauro, et al. 2007). Fathi and Nayif (2013) have evaluated the bond strength of similar adhesive systems following dentin treatment with Er,Cr:YSGG laser when samples did not subjected to the pulpal pressure and they demonstrated a higher CTBS values in comparison to current study values. This indicates that there is a significant negative effect of pulpal pressure on tensile bond strength. A result was parallel to other studies in which bond strength to dentin was decreased with pulpal pressure simulation (Gupta and Tewari, 2006; Hosaka, 2007; Bakry et al., 2009). They impute the reason to shallower penetration of the adhesives into dentin surface in samples with pulpal pressure as confirmed by confocal laser scanning microscopy analysis. Another consideration is that current adhesives contain hydrophilic components, increasing their potential to absorb water (Peumans et al, 2014). HEMA (2-hydroxyethyl methacrylate) is monomer used in all bonding agents used in our study, (Adper single bond, 3M ESPE), (Adper easy one, 3M ESPE), and (Clearfil SE bond, Kurary) to improve wetting and spreading of adhesives on dentin. The application of simulated pulpal pressure in vitro obviously increases connective fluid movement and reveals through-and through water channels in the adhesive Nayif et al (2010). The presence of water within adhesive film may compromise mechanical properties of polymers, such as its tensile bond strength and its modulus of elasticity (Saikaew et al, 2018). Considering these results, decrease in bond strength due to pulpal pressure simulation is expected in our study because HEMA content and lack of smear layer due to laser application. The result of this study demonstrated no significant changes between the different adhesive systems when bonded to dentin treated with laser under SPP. Such result might be possible due to weak acidity in self etch adhesive of limited effectiveness of their primers to demineralize the laser-modified superficial layer and alter the morphological pattern (Nayif et al. 2010). According to previous studies, the degradation of dentin organic substances and the changes in size and ultrastructure of apatite crystals resulting from laser irradiation substantially increase the acid-resistance of lased dentin. Additionally, it has been reported that laser radiation modifies calcium-to-phosphorus ratio, reduces carbon-to-phosphorus ratio and leads to 
the formation of more stable and less acidsoluble compounds, thus reducing dentin susceptibility to acid attack. Therefore, it seems feasible to speculate that an agent with stronger acid such as $35 \%$ phosphoric acid (Single Bond adhesive) will present higher efficiency in removing the dentin layer modified by the laser than an etchant agent with weaker acid potential, such as the acidic monomer in (Clearfil SE Bond self-etching primer or Adper easy Bond).But this was not the case in this study where total etch was not different from other adhesives.

Van Meerbeek et al., (2010) suggested that there was as a strong correlation between the value of bond strength and the failure mode: the higher the bond strength, the higher the rate of cohesive failure. Failure mode analysis of our study revealed that no cohesive failure at resin dentin interface which was in correlation with lower bond strength value for such type of adhesive system in SPP when compared with earlier study without SPP of similar methodology. However all systems evaluated in this study mode of failure shows adhesive and mixed failure pattern with exposed dentin surfaces. In this in vitro study, it can be concluded that that different systems of adhesives applied in simulation of pulpal pressure could not affect the tensile bond strength of resin composite bonded to $\mathrm{Er}, \mathrm{Cr}$ : YSGG prepared dentin.in another word changes in the surface of dentin due to laser treatment render adhesives behavior similar in relation to bond strength.

\section{CONCLUSION}

Within the limitation of this study the different types and systems of adhesives (total and self etch systems) did not affect the conventional tensile bond strengths of composite resin bonded to laser treated dentin under simulated SPP.

\section{REFERENCES}

Buyukhatipoglu I, Ozsevik S, Secilmis A, Usumez A.(2016). Effect of dentin laser irradiation at different pulse settings on microtensile bond strength of flowable resin. Dent Mater J,35, 82-88.

Bakry, A., Nakajima M., Otsuki M., and Tagami J. (2009). Effect of Er:YAG laser on dentin bonding durability under simulated pulpal pressure. J Adhes Dent, 11, 361-368.

Breschi L, Maravic T, Cunha S,Comba A, et al (2018). Dentin bonding systems: From dentin collagen structure to bond preservation and clinical applications. Dent Mater, 34, 78-96.

Cardoso, M., Moretto, S., Carvalho, R., and Russo, R., (2008). Influence of intrapulpal pressure simulation on the bond strength of adhesive systems to dentin. Braz Oral Res, 22, 170-175.

Davari A, Sadeghi M, Bakhshi H. Shear bond strength of an etch-and-rinse adhesive to Er:YAG Laser- and/or phosphoric acid-treated dentin. J Dent Res Dent Clin Dent Prospects 2013; 7: 67-73.

Fathi U, and Nayif MM (2013). Tensile Bond Strength of Resin Composite to Er,Cr:YSGG Lased Dentin Bonded With Different Adhesive Systems. Al Rafidain Dent J, 15, 456-462.

Gernhardt, C., Schaller, H., and Kielbassa, A. (2005). The influence of human plasma used for dentin perfusion on tensile bond strength of different light-curing materials. Am J Den,. 18, 318-22.

Gupta, R., and Tewari, S. (2006). Effect of rotary instrumentation on composite bond strength with simulated pulpal pressure. Oper Dent. 31, 188-96.

Hashimoto, M., Ito, S., Tay, F., Svizero, N., Sano, H., and Kaga, M. (2004). Fluid movement across the resin-dentin interface during and after bonding. J Dent Res, 83,843-848.

Hashimoto, M., Tay, F., Svizero, N., De Gee, A., Felizer, A., and Sano, k. (2006). The effect of common errors on sealing ability of total-etch adhesives. Dent Mater, 22,560-568.

Hosaka, K., Nakajima, M., Yamauti, M., Aksornmuang, J., Ikeda, M., and Foxton, R. (2007). Effect of simulated pulpal pressure on all-in-one adhesive bond strengths to dentine. J Den.35,207-213.

Karadas M and Çaglar I. (2017). The effect of Er:YAG laser irradiation on the bond stability of self-etch adhesives at different dentin depths. Laser Med Sci, 32,967-974.

Moll, K., Park, H., and Haller, B. (2005). Effect of simulated pulpal pressure on dentin bond strength of self-etching bonding systems. Am J Den, 18, 335-9.

Nakajima, M., Hosaka, K., Yamauti, M., Foxton, R., and Tagami, J. (2006). Bonding durability of a self-etching primer system to normal and caries-affected dentin under hydrostatic pulpal pressure in vitro. Am J Dent, 19,147-150. 
Nayif MM, Shimada Y, Ichinose S, Tagami J. (2010). Nanoleakage of current self etch adhesives bonded to artificial carious dentin. Am J Dent, 23, 279-84.

Obeidi, A., Liu. P., Ramp, L., Beck, P., and Gutknecht, N. (2010). Acid-etch interval and shear bond strength of Er,Cr:YSGG laserprepared enamel and dentin. Laser Med Sci, 25,363-369.

Peumans M, De Munck J, Mine A, Van Meerbeek B. Clinical effectiveness of contemporary adhesives for the restoration of non- carious cervical lesions. A systematic review. Dent Mater 2014;30: 1089- 103.

Rosales-Leal, JI., de la Torre-Moreno FJ., and Bravo, M. (2007). Effect of pulp pressure on the micropermeability and sealing ability of etch $\&$ rinse and self-etching adhesives. Oper Dent, 32, 242-250.

Saikaew P, Fu J, Chowdhury A, Carvalho R, Sano H. (2018). Effect of air-blowing time and long-term storage on bond strength of universal adhesives to dentin. Clin Oral Invest, 16, 100-21.
Sauro, S., Pashley, D., Montanari, M., Chersoni, S., Carvalho, R., and Toledano, M. (2007). Effect of simulated pulpal pressure on dentin permeability and adhesion of self-etch adhesives. Dent Mater, 23,705-713.

Tay, F., Pashley, D., Hiraishi, N., Imazato, S., Rueggeberg, F., Salz, U. (2005). Tubular occlusion prevents water-treeing and throughand- through fluid movement in a single-bottle, one-step self-etch adhesive model. J Dent Res, 84,891-896.

Van Meerbeek, B., Peumans, M., Poitevin, A., Mine, A., Van Ende, A., Neves, A., and De Munck, J. (2010). Relationship between bond-strength tests and clinical outcomes. Dent Ma,. 26, $100-121$.

Youssef, M., Quinelato, A., Youssef, F., Pelino, J., Salvadori, M., and Mori, M. (2008). Dentinal surface-cutting efficiency using a high-speed diamond bur, ultrasound and laser. Laser Physics, 18,472-477. 
Table (1): Compositions of the adhesives and resin composite used.

\begin{tabular}{ll}
\hline Materials & Compositions \\
\hline Adper Single Bond 2 & $\begin{array}{l}\text { Silica nanofiller, BisGMA, HEMA, dimethacrylates, ethanol, a methacrylate functional } \\
\text { copolymer of polyacrylic and polyitaconic acids. }\end{array}$ \\
\hline Adper Easy One & $\begin{array}{l}\text { HEMA, Bis-GMA, Methacrylated phosphoric esters, } \\
\text { hexanedioldimethacrylateMethacrylate functionalized Polyalkenoic acid (Vitrebond } \\
\text { Copolymer), Ethanol, Water, Initiators based on camphorquinone. }\end{array}$ \\
\hline Clearfil SE bond, & $\begin{array}{l}\text { Primer: MDP, HEMA, dimethacrylate monomer, water, catalyst. } \\
\text { Bond: MDP, HEMA, dimethacrylate monomer, microfiller, catalyst. }\end{array}$ \\
\hline Filtek Z-250 composite & Filler: zirconia/silica inorganic filler, loading of fillers is $60 \%$ by volume (without silane \\
treatment) with a particle size range of 0.01 to 3.5 microns. \\
Resins: BIS-GMA, UDMA and BIS-EMA
\end{tabular}

Table (2): One Way ANOVA of different adhesive system bond strength under pulpal pressure.

\begin{tabular}{llllll} 
& Sum of squares & Df & Mean square & $F$ & Sig. \\
\hline Between groups & 175.00 & 2 & 87.500 & .389 & .684 \\
\hline Within groups & 3375.500 & 15 & 225.033 & & \\
\hline Total & 3550.500 & 17 & & \\
\hline
\end{tabular}

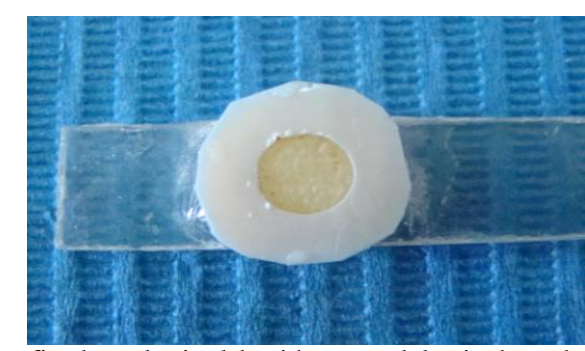

Fig. (1): Crown fixed on plastic slab with exposed dentin through circular punch of $4 \mathrm{~mm}$.

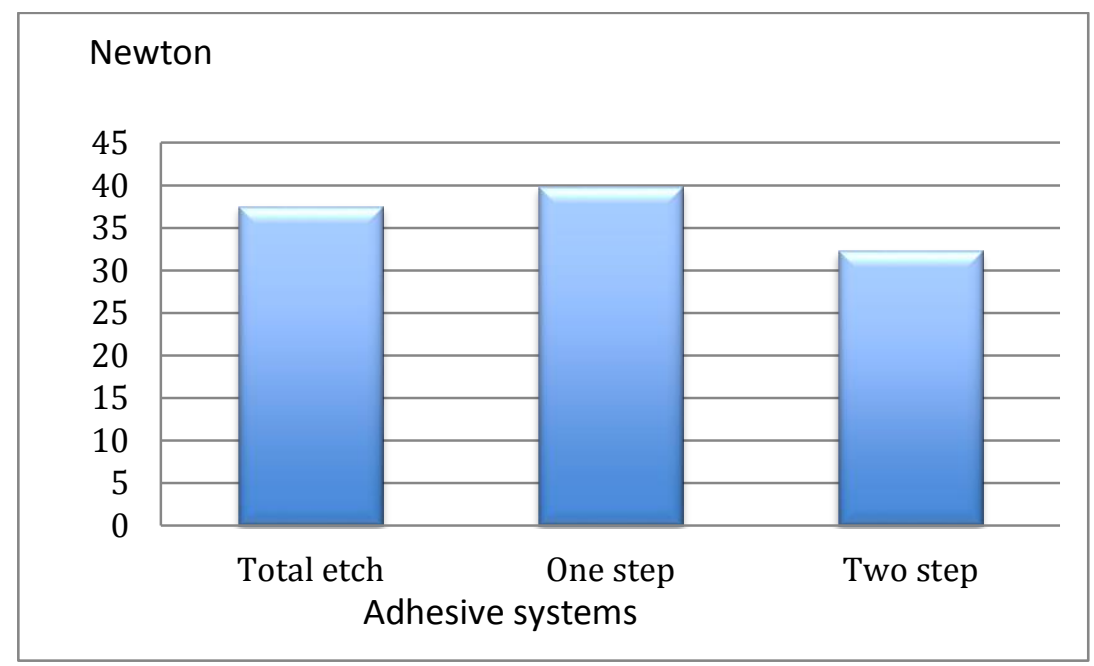

Fig. (2): Mean tensile bond strength of three adhesive systems. 
كاريكهريى سيستهمى يِيوهدهنوسى لهسهر هيّزى بهندى كوميوزت به ديّنتهن مامهلّهى كراوه به

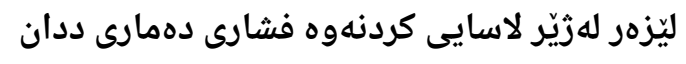

يوخته

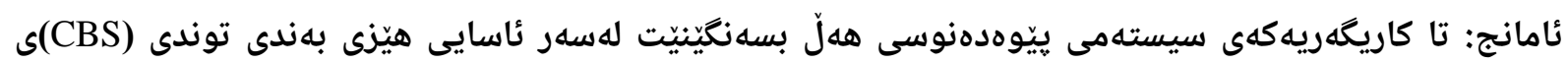

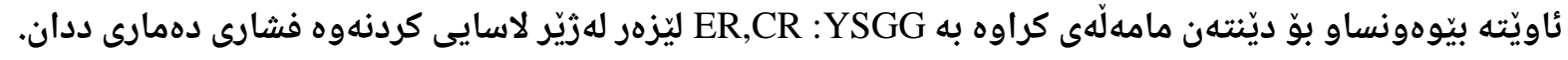

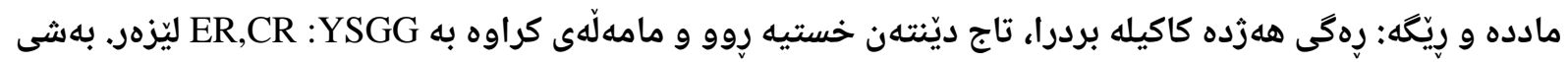

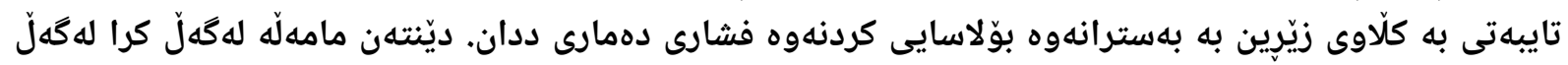

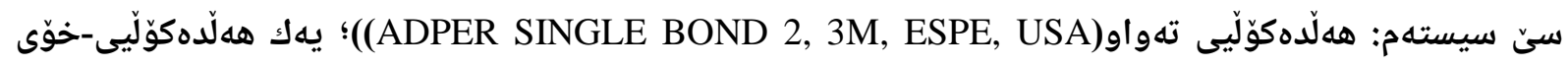

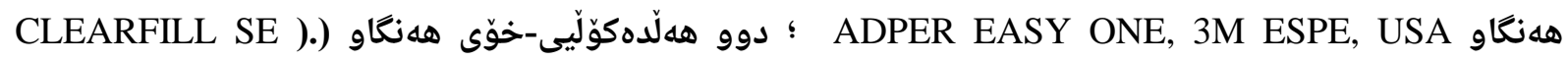
BOND, KURARY MEDICAL,GERMANY

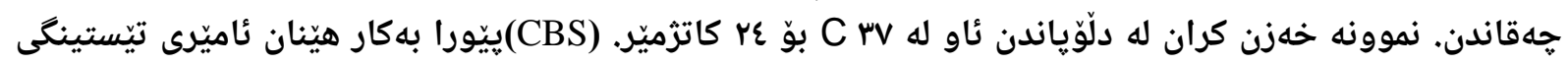

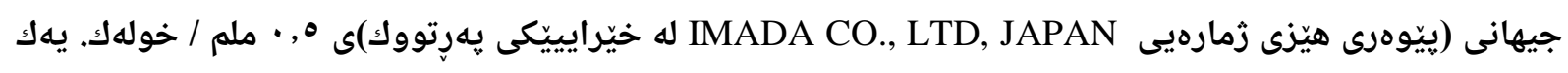

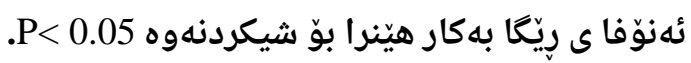

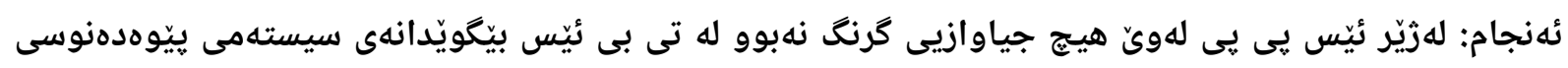

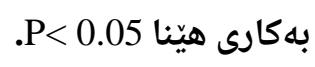

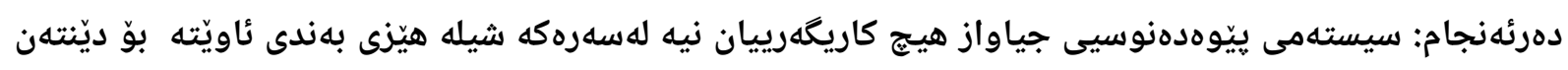

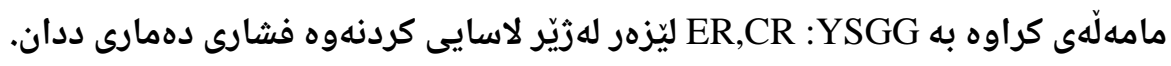
وشهى سهرهكى: يِيوهدهنوسى، هيّزى بهند، فشارى دهمارى ددان ، ليّزهر

الخلاصة

الهدف: لتقيم قوة الربط القابلة للشد في حشوات الرانتج المركب الملصق على سطح العج المعالج بأستخدام ليزر (Er,Cr:YSGG)

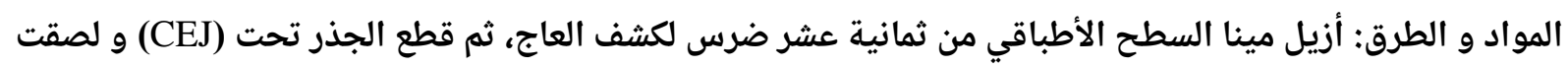

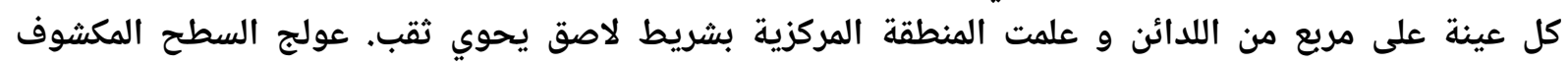

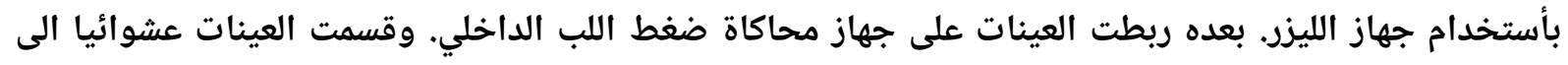

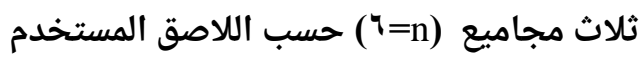
(Adper single bond, 3M ESPE) (Adper easy bond, 3M ESPE) (Clearfil SE bond, Kurary البوب بلاستيكي شفاف و ملأ بالراتنج المركب الهجين، ثم ادخل لولب معدني صغير مع حلقة رأس في الاضافة الهاء

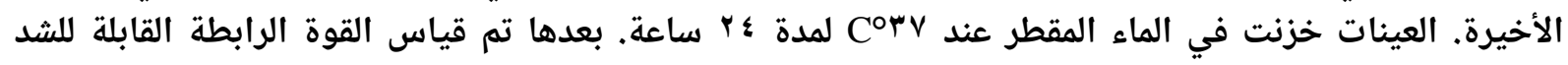

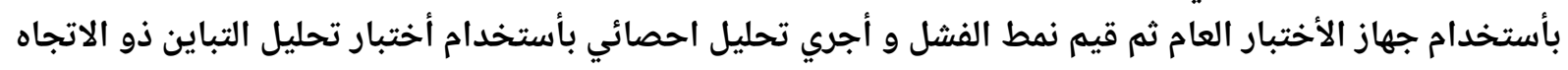
الواحد. النتائج: وجد أن عدم وجود أختلاف معنوي في القوة الرابطة للشد للأنواع المختلفة من الروابط عند محاكاة ضغط

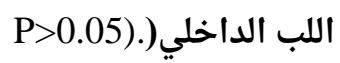
الكلمات الففتاحية: الليزر' ضغط العصب، الالتصاق 